\title{
Review of the Latest Methods of Epidermolysis Bullosa and Other Chronic Wounds Treatment Including BIOOPA Dressing
}

\author{
Magdalena Nita · Jacek Pliszczyński · Maciej Kosieradzki • \\ Piotr Fiedor
}

Received: April 8, 2021 / Published online: July 15, 2021

(C) The Author(s) 2021

\begin{abstract}
Epidermolysis bullosa (EB) is a hereditary genetic skin disorder, classified as a type of genodermatosis, which causes severe, chronic skin blisters associated with painful and potentially life-threatening complications. Currently, there is no effective therapy or cure for EB. However, over the past decade, there have been several important advances in treatment methods, which are now approaching clinical application, including gene therapy, protein replacement therapy, cell therapy (allogeneic fibroblasts, mesenchymal stromal cells), bone marrow stem cell transplant, culture/vaccination of revertant mosaic keratinocytes, gene editing/engineering, and the clinical application of inducible pluripotent stem cells. Tissue engineering scientists are developing materials that mimic the structure and natural healing process to promote skin reconstruction in the event of an incurable injury. Although a cure for EB remains elusive, recent data from animal models and preliminary human clinical trials have raised the expectations of patients, clinicians, and researchers, where modifying the
\end{abstract}

M. Nita · J. Pliszczyński · M. Kosieradzki · P. Fiedor $(\bowtie)$

General and Transplantation Surgery, Medical

University of Warsaw, Nowogrodzka Street 59, 02-

014 Warsaw, Poland

e-mail: piotrfiedor@wp.pl disease and improving patients' quality of life are now considered attainable goals. In addition, the lessons learned from the treatment of EB may improve the treatment of other genetic diseases.

Keywords: Biological dressing; Human skin allograft; Allogenic human skin equivalent; Advanced therapy medicinal product; Epidermolysis bullosa; Rare disease

\section{Key Summary Points}

Epidermolysis bullosa (EB) is a hereditary genetic skin disorder, classified as a type of genodermatosis

Currently, there is no effective therapy or cure for EB

Methods of EB wound treatment include autogenic skin transplantation, gene engineering and tissue engineered skin substitutes

Recent achievements will lead to the production of skin substitutes displaying the basic qualities of natural skin 


\section{INTRODUCTION}

Epidermolysis bullosa (EB) is a group of autosomal dominant and recessive disorders where injury leads to blistering and skin erosion $[1,2]$. Several different subtypes have been described, and the underlying molecular pathology involves mutations in at least ten different genes encoding structural proteins within the dermoepidermal junctions (DEJ) or primary epidermal keratinocytes. One of the most severe clinical forms of EB is recessive dystrophic EB (RDEB). This condition is characterised by widespread fragility of the skin and mucous membranes [3].

In general, wounds and blisters are followed by scarring and an increased incidence of squamous cell carcinoma, which represents the main cause of death in young adults with RDEB [4]. Affected individuals also suffer from many non-skin-related complications, including chronic anaemia, osteopenia and tactile hallucination [5]. RDEB is caused by loss-of-function mutations in the gene encoding type VII collagen, COL7A1 [6].

Currently, there is no causal cure for EB. Phenytoin, psoralen plus UVA photochemotherapy, tetracycline, systemic glucocorticoids, and antimalarial drugs are not very effective, and EB therapy is mainly focused on local wound healing and avoiding injury. Surgical treatment consists of skin transplant, repairing mitten hand deformities, and splinting and dealing with visceral complications (e.g., jejunostomy tubes, oesophageal dilation). Other important complementary therapies include physiotherapy, genetic counselling, aggressive infection treatment, nutritional supplementation, and regular monitoring for malignant skin tumours. Skin and wound care in EB is specific to both the type of EB and the individual wounds of each child. The availability of dressings and personal preference of the patient are also important when choosing materials. Although an ideal dressing for EB is yet to be developed, many suitable dressings are currently available. It is difficult for wounds to heal, and chronic wounds are common. Factors that adversely affect healing include anaemia, malnutrition, infection, and itching. Parallel advances in gene and stem cell therapies are approaching combinatorial therapies that promise clinically significant and lifelong improvement [7-9]. Recent studies using hematopoietic stem cells, mesenchymal stromal cells, or stem cells in the treatment of EB have demonstrated the potential to treat severe cases permanently and effectively. In addition, advances in the use of gene therapy and gene editing techniques, combined with the development of induced pluripotent stem cells from patients with $\mathrm{EB}$, allow for autologous therapies derived from a renewable patient-specific cell population $[10,11]$.

The low success rate of conventional wound management methods necessitates the production of skin substitutes, such as a layer of keratinocytes inoculated on a biocompatible carrier. This creates a microenvironment suitable for both fibroblasts and epithelial cells, which can assist in repairing the wound and reducing the undesirable results of the abovementioned methods. The multidisciplinary field of tissue engineering was created through the collaboration of biomedical and biomaterial engineers, cell and molecule scientists and clinicians with the aim to develop viable, advanced medical devices to restore the normal functions of damaged tissue. Thanks to this interdisciplinary field, many bioengineered skin substitutes have been developed as an appropriate dressing over the damaged area to treat healing-resistant wounds, which can be as effective or even surpass conventional woundhealing methods $[8,12]$.

In this article, we describe recent methods of treating genodermatoses, using EB as an example, and present a discussion of their advantages and limitations as effective therapies. Thsi study was approved by an ethics committee (KB / 2019 14/01/2019; KB / 177/2015). This article is based on previously conducted studies and does not contain any new studies with human participants or animals performed by any of the authors. 


\section{METHODS OF WOUND TREATMENT}

\section{Dressings}

Recently developed innovative dressing materials include bioelectric dressings, double-layered silk gelatine and dressings with new ointments such as Triterpine. An "ideal" burn wound dressing was described as having nonadhesive, absorbent properties and antimicrobial activity. Goertz et al. [13] described a solidifying gel that dissolves in a specific temperature range, providing an interface that is better accepted by patients with superficial wounds. Their new gel is liquid at room temperature and hardens to a gel consistency at normal body temperature or above, which causes less pain and leads to better results regarding staining, leakage, and odour compared to silver sulfadiazine gauze. Another promising dressing recently described in nonhuman studies involves a gelling dendrite dressing based on hydrogel, with three-stage bonds that can dissolve on demand. The possibility of applying the gel, which solidifies in a few minutes, greatly simplifies the process of applying the dressing. In vivo studies have shown that these gels ensure effective haemostasis and prevent infection while providing a moist wound-healing environment. An important feature of this dressing is the ability of clinicians to dissolve the dressing on demand for atraumatic removal [7]. Antibacterial gel dressings based on chitosan (Opticell $\mathrm{Ag}^{+}$) have recently been introduced, which provide a moist, adaptable, highly absorbable antimicrobial dressing to reduce dressing changes and alleviate pain. Catrix powder (bovine cartilage powder; Cranage Healthcare International) is a medically recommended alternative, and early studies suggest faster healing of blisters after Catrix application [14]. Honey, in the form of impregnated dressings and ointments, is effective in both the treatment of chronic wounds and reducing the biological load [15]. Cutimed Sorbact dressings remove bacteria through hydrophobic interactions. They are coated with a fatty acid derivative that attracts bacteria to the dressing, where they are bound [16]. Preliminary studies have shown that this dressing is effective for wound healing in people with chronic EB-related wounds. Dressings containing polyhexanide, such as Suprasorb X1 PHMB (Activa Healthcare, Lohmann \& Rauscher, UK), provide antimicrobial treatment for critically colonised and infected wounds, and they are recommended for long-term application [13]. The polymer membrane dressing (PolyMem, Ferris, OH, USA) contains a cleaning agent (surfactant), which reduces the biological load and allows the healing of resistant wounds. Polymeric membrane dressings have the advantage of being "self-contained" without the need for a non-adherent primary or secondary dressing to protect or manage exudation. The frequency of dressing changes depends on personal choice, available time, and level of exudation [17]. Infected or critically colonised wounds require more frequent dressing changes. The use of honey products and polymeric dressings on the membrane initially increases the amount of exudate, so before starting, the patient must commit to daily dressing changes.

Ibuprofen-soaked (Biatain-Ibu) dressings have proven to be helpful for some wounds; however, they are not licensed for children aged under $12-15$ years [18].

\section{Autogenic Skin Transplantation}

Skin transplantation is an old technique that was rediscovered during World War I and II, becoming the main way to heal wounds. Padget and Hood invented the dermatome, an indispensable device still used to this day to collect large portions of skin. In 1929, Brown developed a split-thickness skin transplantation technique, distinguishing between full-thickness, medium-thickness, and epidermal transplants [19].

Skin grafts can be categorised by graft thickness, geometry, and source. Depending on the thickness of the graft, a distinction is made between split-thickness skin grafts (SSG) and full-thickness skin grafts (FTSG) [20].

Split-thickness skin grafts consist of epidermis and some layers of dermis. Different types 
of SSGs can be identified: thin SSG (0.15-0.3 mm), medium SSG (0.3-0.45 mm), and thick SSG (0.45-0.6 mm) [21].

FTSG consist of epidermis, dermis, and various layers of subcutaneous tissue. The amount of dermis plays a key role in determining the mechanical, functional, aesthetic, and transplant trophic properties. In fact, a thicker transplant has better mechanical, functional, and aesthetic properties, but neovascularisation and revascularisation occur with some difficulties and last for at least 5 days [21, 22].

Split-thickness skin grafts are characterised by a poor cosmetic outcome. In addition, SSGs contain fewer tissues requiring revascularisation after implantation; therefore, thin grafts can be used to treat wounds with reduced blood supply [21].

The method employed for supplying and covering skin defects (FTSG or SSG) varies depending on the centre and the experience of the surgeon. However, there is little evidence in the literature of the superiority of one method over the other, and long-term results may vary slightly. There are several factors to consider: availability of donor sites and their potential to heal, delaying the onset of contraction, the likelihood of a successful transplant, and patient selection [21].

It has been suggested that FTSG may delay contract recurrences better than SSG. However, the use of FTSG is often less successful than applying SSG, leading to potential scar formation. In addition, the site of skin collection shows much poorer healing in patients with $\mathrm{EB}$, limiting the skin surface that can act as a source and increasing the likelihood of scar contracture at the site of collection [23].

Problems can be minimised by only collecting the epithelium as a "split" graft. With this technique, healing is faster, and the epithelium can be collected from any place where there are no damaged skin and blisters with purulent substance. Recurrent contracture is more common within the first 6 months, but healing at the donor site is more predictable and usually occurs within 2 weeks. The authors have used this technique several times [22].

\section{Gene Engineering}

Until recently, EB treatment only consisted of symptomatic treatment. With advances in the field of genetics, new and exciting therapies are being proposed to address the cause of skin fragility in these patients, including replacement of the abnormal protein (e.g., collagen VII in RDEB) and bone marrow transplantation.

Recent studies have suggested that the delivery of allogeneic fibroblasts to the skin of patients with RDEB may be beneficial for improving skin adhesion and increasing the deposition of type VII collagen at the dermoepidermal junction. There is promising data in patients with RDEB treated with immune myeloablative chemotherapy and allogeneic stem cell transplantation, which resulted in better wound healing, reduced blistering, and increased collagen VII deposition at the dermoepidermal junction. Viral vectors are the most common form of gene therapy for the treatment of genetic disorders. Retroviral, lentiviral, and adenoviral vectors have been developed for RDEB gene therapy. One study used a retroviral vector for the transduction of fibroblasts, which were then evaluated and injected into a mouse model of RDEB. Transduced fibroblasts have been shown to express functional C7, embed it as mature anchor fibrils, and ensure improvement based on both in vitro and in vivo evaluation. The first application of gene therapy in RDEB patients was a retroviral vector used for the transduction of keratinocytes containing full-length human COL7A1. Transduced keratinocytes were then cultured in a good manufacturing practice device to generate corrected epidermal sheets for autologous therapy. These external autologous transplants were tolerated for 12 months with positive results. Adenoviral vectors have been similarly used to correct RDEB cells with both fibroblasts and keratinocytes and then to determine the induced pluripotent stem cell (iPSC) line for future therapeutic applications. These improved iPSCs were then differentiated into keratinocytes that were able to express C7 and transform into layers both in vitro and in vivo. Lentiviral vectors have also been developed for C7 gene therapy. Recently, a 
lentiviral vector containing the codon-optimised COL7A1 gene was developed and used to correct RDEB fibroblasts. Corrected fibroblasts have been shown to express full-length functional C7 in vitro and embed C7 in DEJ in skin grafts in immunodeficient mice. These approaches may be useful to develop the combinatorial therapies needed to address the systemic problems of this disease [24-28].

Although encouraging, more research is needed to determine the long-term safety and effectiveness of this modality. Until then, the goals of treatment are to optimise wound healing and minimise disability caused by blisters $[29,30]$.

\section{Tissue Engineered Skin Substitutes}

Tissue engineering is rapidly progressing from basic research to commercial applications.

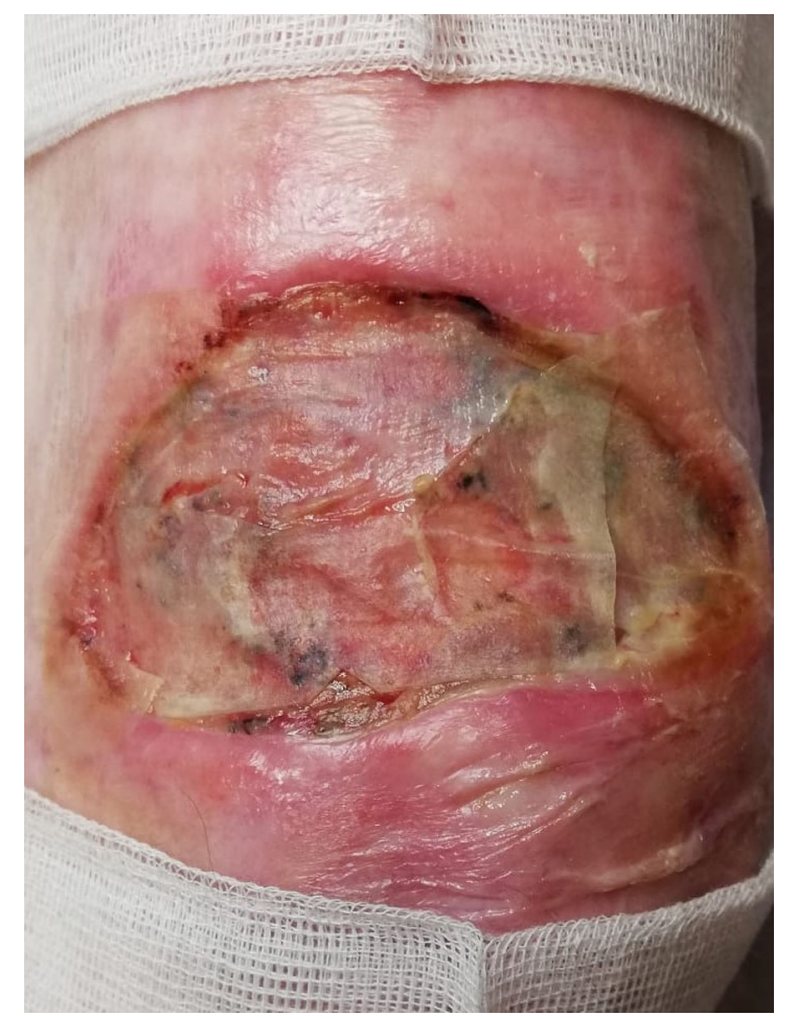

Fig. 1 Day 0, procedure: wound covered with the prepared graft (allogenic human skin equivalent)
Many skin substitutes have been produced by in vitro methods. They are available in various forms, mainly classified into epidermal, dermal, and dermoepidermal or composite skin analogues, which may consist of cell-based or cellfree scaffolds [31].

Biocompatibility, biodegradability, non-carcinogenic cross-linking, cost-effectiveness, risk of infectious diseases, and prevention of immune system stimulation are all factors that need to be considered to create safe and highquality engineering requirements for the skin. The main approach in the engineering of skin substitutes is the culture of primary skin cells, such as stem cells, fibroblasts, keratinocytes, melanocytes, and Langerhans cells, in a natural or biosynthetic scaffold mimicking the threedimensional (3D) structure of normal cells [32].

Although there is a wide range of tissue engineering products available on the market, almost none of them meet all the requirements for real skin, including deep skin processes, appropriate vascularisation, and normal pigmentation [32].

The first product to apply tissue engineering to $\mathrm{EB}$ is the autologous cultured epidermal substitute (CES). Pioneering work by Green [33] demonstrated that it is possible to grow epidermal keratinocytes as layered sheets from a single cell suspension, and multilayer sheets obtained in this way are very effective for healing burns and wounds in patients with EB.

Along with the acceptable demand for skin components, several types of two-layer skin substitutes consisting of both epidermal and dermal components have been developed. Bell et al. [34] developed a cultured skin substitute (CSS), the equivalent of live skin, which consists of a collagen gel with fibroblasts covered with keratinocytes. Boyce [35] developed a CSS consisting of collagen/glycosaminoglycan with fibroblasts deposited by keratinocytes. Kuroyanagi et al. [36] also developed a cultured skin substitute consisting of a spongy collagen matrix with fibroblasts applied over keratinocytes. These two-layer skin substitutes are designed to be a permanent cover for FTSGs $[31,37,38]$. Recent tissue engineered skin substitutes are included in Table 1. 


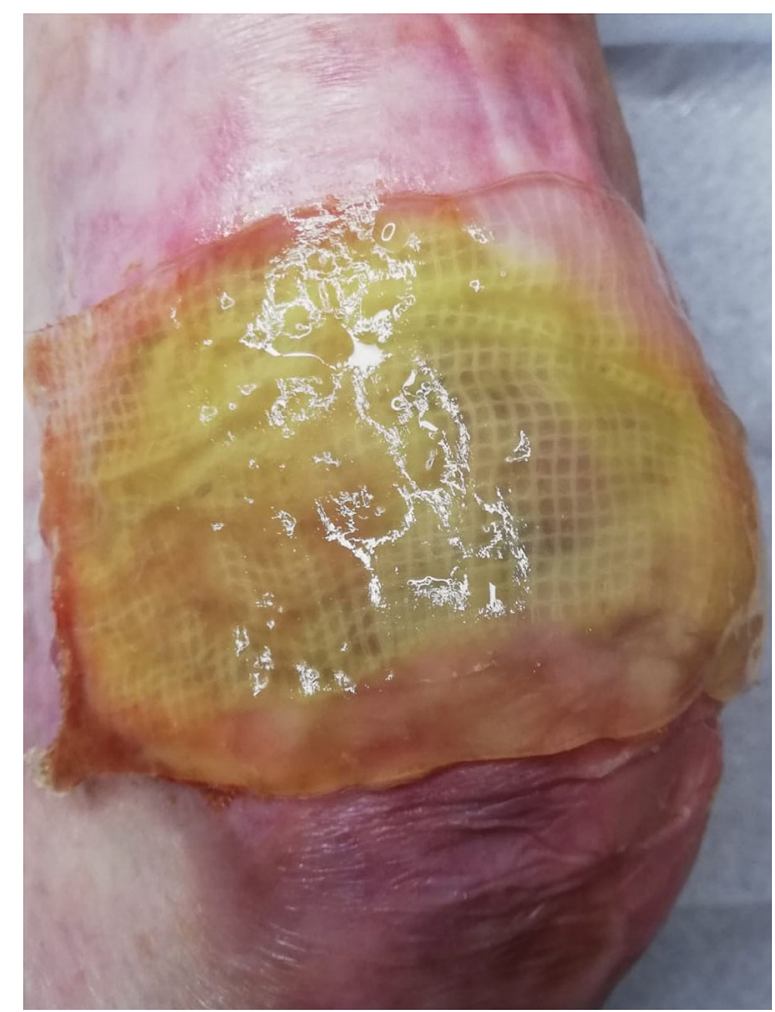

Fig. 2 BIOOPA dressing: an acellular human skin allograft seeded with multipotent stem cells

\section{DISCUSSION}

Despite tremendous progress in understanding the molecular genetics and the underlying pathological mechanisms of EB over the past few decades, there is still no cure. There have been many preclinical attempts to develop new treatments for EB. The goal of these therapeutic approaches was to correct the primary genetic defect at the DNA, mRNA, or protein level using induced pluripotent stem cells (iPSC) or keratinocyte-based gene correction, the use of protein therapies for antisense oligonucleotides, and the use of medications that trigger premature termination codon reading. Other potential treatment strategies include diseasemodifying therapies that relieve the symptoms and deal with the inflammatory and fibrotic processes responsible for specific EB phenotypes. Although such reports are promising, any potentially effective EB therapies are currently at preclinical stage and are not yet available on the market. Thus, the search for new methods of treatment is still of great importance. Blistering and wound formation along with accompanying pain and discomfort is part of life of patients with EB. Pain is difficult to manage; patients very often reported reluctance to use painkillers because of side effects. Patients with EB are also sensitive to heat because of the inability of skin to sweat effectively. Another difficulty is the application and change of dressing. This process depends on size and positioning of wounds and may be time consuming. Patients reported that preparation and application of dressing may take from $30 \mathrm{~min}$ to $7 \mathrm{~h}$. Patients also reported dressing adhesion to fragile skin, even those designed to be low adherent. Tissue engineered skin substitutes seem to be the perfect agent for treatment of wounds of patients with CF and other chronic wounds [43]. The complex EB phenotype triggers a cascade of secondary pathological consequences; therefore, successful treatment will likely require a combinatorial strategy. Although the use of HCT to treat EB appears promising, it is a procedure with inherent risk, including transplant failure, graft versus host disease, a transiently compromised immune system, and side effects resulting from the chemotherapy regimen. Although the use of HCT for EB treatment carries an inherent risk and not all treated patients show significant improvement, the potential for HCT or other stem cell therapies is promising and should be continued and improved. Studying the biological mechanisms of stem cell therapies such as HCT and gene therapy will be valuable in guiding our future approaches. The subset or subsets of cells from an HCT transplant that are effective in producing $\mathrm{C} 7$ and mediating wound healing have not been sufficiently characterised, although some studies have provided insight into which cells may be responsible. Identifying these subgroups may help modify the transplant protocol or improve therapy in a way that promotes greater $\mathrm{C} 7$ production in patients who do not respond well to HCT. EB wounds are different in individuals, but there are common problems such as risk of infection, 
Table 1 Recent tissue engineered skin substitutes

\begin{tabular}{|c|c|}
\hline Type & Description \\
\hline Apligraf & $\begin{array}{l}\text { Two-layer skin substitute composed of dermis and epidermis equivalents. The epidermis and skin layers contain } \\
\text { appropriately cultured keratinocytes and fibroblasts obtained from newborn foreskin. Bovine type I collagen } \\
\text { is also present in the skin layer, which promotes the growth and differentiation of cells [37]. It has a positive } \\
\text { influence on wound healing, providing extracellular matrix components, essential growth factors, and } \\
\text { cytokines. A decrease in immune system stimulation in the recipient's body has been reported because } \\
\text { Apligraf does not contain antigen-presenting cells, such as macrophages and dendritic cells. There have been } \\
\text { no reports of the rejection of bovine collagen or alloantigens expressed on keratinocytes or fibroblasts [39]. } \\
\text { Apligraf has a short shelf-life, and its use is associated with high costs. Nevertheless, studies have reported a } \\
\text { positive effect of this dressing in EB wound care [40] }\end{array}$ \\
\hline Biobrane & $\begin{array}{l}\text { Synthetic two-layer skin substitute consisting mainly of type I swine collagen around a 3D nylon filament, with } \\
\text { a layer of ultra-thin semi-permeable silicone film as an epidermal layer, which controls the loss of skin fluid } \\
\text { [41] }\end{array}$ \\
\hline BIOOPA & $\begin{array}{l}\text { BIOOPA is an advanced therapy medicinal product, made of an acellular human skin matrix prepared from } \\
\text { superficial layers of human skin }(10 \times 10 \mathrm{~cm}) \text { harvested from a deceased donor. The acellular dermal matrix } \\
\text { is an allograft tissue that is chemically processed to remove all epidermis and dermis cells with molecular and } \\
\text { physiological structure of collagen fibers. The structure is sterilized by radiation, and then the matrix is } \\
\text { colonized with } 30 \text { million mesenchymal stem cells derived from Wharton's jelly in human albumin solution. } \\
\text { This skin substitute does not induce patient immune response because of the removal of all cells. } \\
\text { Additionally, acellularization reduces the risk of disease transmission }[29,30] \text { (Figs. 1, 2, 3) }\end{array}$ \\
\hline OrCelTM & $\begin{array}{l}\text { Two-layer composite consisting of a type I bovine collagen matrix, into which cultured neonatal keratinocytes } \\
\text { and foreskin fibroblasts are implanted to form the dermis [41]. Its scaffolding is thicker than that of Apligraf, } \\
\text { and the patient's cells penetrate the 3D scaffold after transplantation. OrCelTM is used in patients with } \\
\text { recessive dystrophic EB (RDEB) [42]. In addition, it stimulates wound healing through cytokines and growth } \\
\text { factors such as TGF- } \alpha \text {, fibroblast growth factor- } 1 \text { and keratinocyte-1 growth factor, which are released at the } \\
\text { affected site. However, bovine collagen increases the risk of transplant rejection and disease transmission [38] }\end{array}$ \\
\hline
\end{tabular}

delicate skin, exudate, and malodour. EB wounds cover large areas of patients' bodies and are referred to as hard-to-heal wounds.

In addition, wound healing is a complex process, and it is unclear whether there are many types of cells, which are responsible for important processes needed for sufficient longterm improvement of EB skin, i.e., wound healing, C7 production, reproduced epithelium, and long DEJ thermal stability. There may certainly be immune cells that are important in the early stages of wound healing and for extracellular matrix production that do not contribute to long-term skin populations. On the contrary, there may be some subsets of stem cells, such as
MSCs or blood-derived stem cells, which contribute to the cellular compartments of wounded skin by differentiation or transdifferentiation, but which require specific conditions and time to yield significant therapeutic effects beyond the initial waves of differentiated immune cells. It is necessary to carefully analyse these aspects to understand the complexity associated with using stem cell therapy in the treatment of EB. Additional therapies include antifibrotic or anti-inflammatory drugs, C7 protein therapy, and treatment with methods other than non-stem-cell therapy, such as treatment with genetically modified cells. 


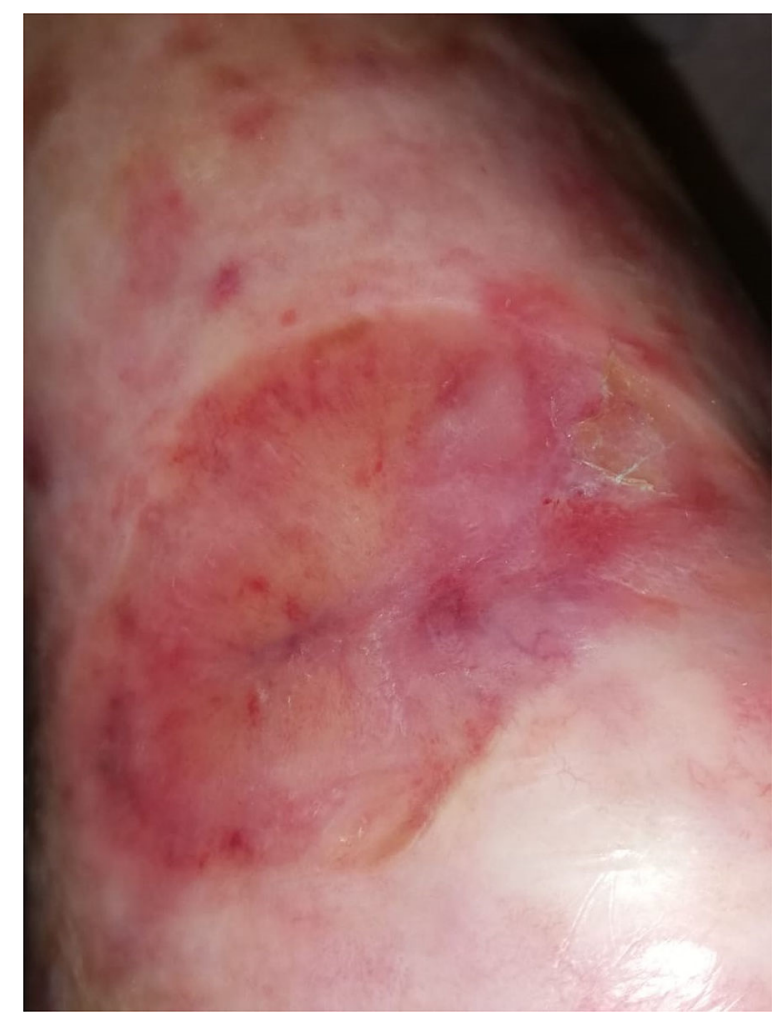

Fig. 3 Result at 30-day follow-up. All examination techniques revealed host-cell infiltration and neovascularisation of the biological dressing. It was characterised by low immunogenicity, as confirmed by histopathology and in vitro $\mathrm{T}$-cell proliferation assays

In conclusion, recent data on animal models and preliminary clinical trials have created significant hope for the development of new and effective EB therapies. Although the promise of a cure is still elusive, several disease-modifying therapies are emerging, and with further refinement and additional clinical testing, translational research in EB is significant and is gradually changing the lives of patients for the better. The lessons learned from EB treatment may have a significant impact on improving the management of other forms of EB and other genetic diseases.

The concept of treating inherited disorders of connective tissue with bone morrow transplant is not new. In fact, the history of EB is somewhat analogous to research conducted approximately 2 decades ago on osteogenesis imperfecta, a genetic disorder that manifests as excessive bone fragility with cracking resulting from a defective type I collagen gene. A series of experiments conducted using the allogeneic bone marrow cells of children with severe osteogenesis defect was carried out following encouraging preclinical trials [44]. Preliminary observations indicated a significant improvement in the mineral content of the body and the microscopic bone structure, which were associated with a reduced frequency of fractures and accelerated growth.

However, the observed clinical improvement was not maintained over time in this group of patients, raising questions about the regenerative capacity of donor-derived mesenchymal progenitor cells, and the lack of persistent donor osteogenesis was considered to reflect an internal program or exogenous signalling environment that suppressed the ability of the transmitted stem cells to differentiate [45].

Based on the latest applications of different types of stem cells (embryonic, prenatal, and adult stem cells), endothelial cells, and melanocytes, combined with significant improvements in the engineering of biocompatible materials such as collagen, HA, elastin, polylactic acid, polylactic-co-glycolic acid, and polyethylene glycol, there is now hope for the effective treatment of incurable wounds. Recent achievements will lead to the production of skin substitutes displaying the basic qualities of natural skin, including sweat glands and hair bulbs, as well as even pigmentation and improved healing of scars in the future [31]. However, further research and efforts are crucial for creating truly natural skin-mimicking substitutes. There has been significant progress towards treating patients with EB through different approaches. However, the current approaches are not a cure for this destructive disease, and the risks of some of these procedures should be weighed against their potential benefits. Advanced and innovative strategies with improved safety profiles, which are currently being developed, are clearly required for the successful treatment of this group of currently incurable diseases. 


\section{PERSPECTIVES}

The future of skin regeneration and wound healing lies in the fields of tissue engineering and regenerative medicine. To obtain an ideal skin substitute, one should consider a variety of features, such as improved vascularity through the application of bioreactors to support vascular formation, longer life, and integration with the tissue of the host. Scaffold polymers, growth factors, and cell lines should ideally mimic the natural structure and function of the skin in the most efficient way. To this end, the addition of melanocytes and hair follicles to scaffolds produced with 3D technology should be considered. Microfluidic dermal printing and automatic tissue paper printing are new techniques that will revolutionise tissue engineering strategies. Skin substitutes are currently attracting a lot of attention, and much experimental research is required to improve the safety and effectiveness of stem cells and engineering materials to meet the demand for high-quality and profitable products manufactured according to standard protocols.

Progress is being made, but there is still much to be done to achieve a cure for EB. Future approaches should be forward thinking. For example, regarding gene therapy, it may be safer and more beneficial in the long term to fix the gene rather than provide an artificial, external source of cells. From a stem cell point of view, the use of stem cells with an internal therapeutic benefit, such as hematopoietic stem cells, may provide a better systemic benefit than treatment with other cellular options [26-28]. While difficult, fixing the genetic component or the cellular component of EB may be the best approach to achieving lasting benefits.

\section{ACKNOWLEDGEMENTS}

We thank the entire BIOOPA team, all those who at some stage of their work helped to create this manuscript. Especially thanks to: C. Kowalewski $^{1}$, K. Woźniak ${ }^{1}$, A. Eljaszewicz ${ }^{2}$, M. Moniuszko ${ }^{2,3}$, A. Kamiński ${ }^{4}$, D. Śladowski ${ }^{4}$ Z. Zimek ${ }^{5}$. ${ }^{1}$ Department of Dermatology, Medical
University of Warsaw, ${ }^{2}$ Department of Regenerative Medicine and Immune Regulation, Medical University of Białystok, ${ }^{3}$ Department of Allergology and Internal Medicine, Medical University of Białystok, ${ }^{4}$ Department of Transplantology and Central Tissue Bank, Medical University of Warsaw, ${ }^{5}$ Institute of Nuclear Chemistry and Technology.

Funding. This study was financially supported by The National Center for Research and Development under the project name "Prevention Practices and Treatment of Civilizations Diseases-STRATEGMED" (Grant no. STRATERMED2/269807/14/NCBR/2015). The journal's Rapid Service Fee was funded by the Medical University of Warsaw.

Authorship. All named authors meet the International Committee of Medical Journal Editors (ICMJE) criteria for authorship for this article, take responsibility for the integrity of the work as a whole, and have given their approval for this version to be published.

Author Contributions. All authors contributed to the study conception and design. The first draft of the manuscript was written by Magdalena Nita, Jacek Pliszczyński, Maciej Kosieradzki, and Piotr Fiedor. All authors commented on previous versions of the manuscript. All authors read and approved the final manuscript.

Disclosures. Magdalena Nita, Jacek Pliszczyński, Maciej Kosieradzki, and Piotr Fiedor have nothing to disclose.

Compliance with Ethics Guidelines. This study was approved by an ethics committee (KB / 2019 14/01/2019; KB / 177/2015). This article is based on previously conducted studies and does not contain any new studies with human participants or animals performed by any of the authors.

Open Access. This article is licensed under a Creative Commons Attribution-NonCommercial 4.0 International License, which permits any non-commercial use, sharing, adaptation, 
distribution and reproduction in any medium or format, as long as you give appropriate credit to the original author(s) and the source, provide a link to the Creative Commons licence, and indicate if changes were made. The images or other third party material in this article are included in the article's Creative Commons licence, unless indicated otherwise in a credit line to the material. If material is not included in the article's Creative Commons licence and your intended use is not permitted by statutory regulation or exceeds the permitted use, you will need to obtain permission directly from the copyright holder. To view a copy of this licence, visit http://creativecommons.org/licenses/by$\mathrm{nc} / 4.0 /$.

\section{REFERENCES}

1. Fine JD, Eady RA, Bauer EA, Briggaman RA, Bruckner-Tuderman L, Christiano A, et al. Revised classification system for inherited epidermolysis bullosa: report of the Second International Consensus Meeting on diagnosis and classification of epidermolysis bullosa. J Am Acad Dermatol. 2000;42(6):1051-66.

2. Mariath LM, Santin JT, Schuler-Faccini L, Kiszewski AE. Inherited epidermolysis bullosa: update on the clinical and genetic aspects. An Bras Dermatol. 2020;95(5):551-69.

3. Aumailley M, Has C, Tunggal L, Bruckner-Tuderman L. Molecular basis of inherited skin-blistering disorders, and therapeutic implications. Expert Rev Mol Med. 2006;8(24):1-21.

4. Condorelli AG, Dellambra E, Logli E, Zambruno G, Castiglia D. Epidermolysis bullosa-associated squamous cell carcinoma: from pathogenesis to therapeutic perspectives. Int J Mol Sci. 2019;20(22):5707.

5. Reyes ML, Cattani A, Gajardo H, Garcia C, McGrath JA, Palisson F. Bone metabolism in children with epidermolysis bullosa. J Pediatr. 2002;140(4):467-9.

6. Varki R, Sadowski S, Uitto J, Pfendner E. Epidermolysis bullosa. II. Type VII collagen mutations and phenotype-genotype correlations in the dystrophic subtypes. J Med Genet. 2007;44(3):181-92.

7. Hasatsri S, Angspatt A, Aramwit P. Randomized clinical trial of the innovative bilayered wound dressing made of silk and gelatin: safety and efficacy tests using a split-thickness skin graft model. Evid
Based Complement Alternat Med. 2015;2015: 206871.

8. Blanchet-Bardon C, Bohbot S. Using Urgotul dressing for the management of epidermolysis bullosa skin lesions. J Wound Care. 2005;14(10):490-1 (4-6).

9. Larouche D, Cantin-Warren L, Desgagne M, Guignard R, Martel I, Ayoub A, et al. Improved methods to produce tissue-engineered skin substitutes suitable for the permanent closure of full-thickness skin injuries. Biores Open Access. 2016;5(1):320-9.

10. Marinkovich MP, Tang JY. Gene therapy for epidermolysis bullosa. J Invest Dermatol. 2019;139(6): 1221-6.

11. Golchin A, Farahany TZ, Khojasteh A, Soleimanifar F, Ardeshirylajimi A. The clinical trials of mesenchymal stem cell therapy in skin diseases: an update and concise review. Curr Stem Cell Res Ther. 2019;14(1):22-33.

12. Przekora A. A concise review on tissue engineered artificial skin grafts for chronic wound treatment: can we reconstruct functional skin tissue in vitro? Cells. 2020;9(7):1622.

13. Goertz O, Abels C, Knie U, May T, Hirsch T, Daigeler A, et al. Clinical safety and efficacy of a novel thermoreversible polyhexanide-preserved wound covering gel. Eur Surg Res. 2010;44(2):96-101.

14. King S. Catrix: an easy-to-use collagen treatment for wound healing. Br J Community Nurs. 2005;10(9): S31-4.

15. Molan P, Rhodes T. Honey: a biologic wound dressing. Wounds. 2015;27(6):141-51.

16. Powell G. Evaluating Cutimed Sorbact: using a case study approach. Br J Nurs. 2009;18(15):S30 (S2-6).

17. Benskin LL. PolyMem((R)) Wic((R)) Silver((R)) rope: a multifunctional dressing for decreasing pain, swelling, and inflammation. Adv Wound Care (New Rochelle). 2012;1(1):44-7.

18. Gottrup F, Jorgensen B, Karlsmark T, Sibbald RG, Rimdeika R, Harding K, et al. Less pain with BiatainIbu: initial findings from a randomised, controlled, double-blind clinical investigation on painful venous leg ulcers. Int Wound J. 2007;4(Suppl 1): 24-34.

19. Serra R, Rizzuto A, Rossi A, Perri P, Barbetta A, Abdalla $\mathrm{K}$, et al. Skin grafting for the treatment of chronic leg ulcers-a systematic review in evidencebased medicine. Int Wound J. 2017;14(1):149-57. 
20. Davis WJ 3rd, Wu C, Sieber D, Vandevender DK. A comparison of full and split thickness skin grafts in radial forearm donor sites. J Hand Microsurg. 2011;3(1):18-24.

21. Braza ME, Fahrenkopf MP. Split-thickness skin grafts. Treasure Island: StatPearls; 2021.

22. MacFarlane DF. Current techniques in skin grafting. Adv Dermatol. 2006;22:125-38.

23. Osman OF, Emara S. Extended use of full-thickness skin grafts, employing variable donor sites. World J Plast Surg. 2018;7(2):159-65.

24. Jackow J, Titeux M, Portier S, Charbonnier S, Ganier C, Gaucher S, et al. Gene-corrected fibroblast therapy for recessive dystrophic epidermolysis bullosa using a self-inactivating COL7A1 retroviral vector. J Invest Dermatol. 2016;136(7):1346-54.

25. Siprashvili Z, Nguyen NT, Gorell ES, Loutit K, Khuu $P$, Furukawa LK, et al. Safety and wound outcomes following genetically corrected autologous epidermal grafts in patients with recessive dystrophic epidermolysis bullosa. JAMA. 2016;316(17): 1808-17.

26. Sebastiano V, Zhen HH, Haddad B, Bashkirova E, Melo SP, Wang P, et al. Human COL7A1-corrected induced pluripotent stem cells for the treatment of recessive dystrophic epidermolysis bullosa. Sci Transl Med. 2014;6(264):264ra163.

27. Wagner JE, Ishida-Yamamoto A, McGrath JA, Hordinsky M, Keene DR, Woodley DT, et al. Bone marrow transplantation for recessive dystrophic epidermolysis bullosa. N Engl J Med. 2010;363(7): 629-39.

28. Chen M, Kasahara N, Keene DR, Chan L, Hoeffler WK, Finlay D, et al. Restoration of type VII collagen expression and function in dystrophic epidermolysis bullosa. Nat Genet. 2002;32(4):670-5.

29. Nita M, Pliszczynski J, Kowalewski C, Wozniak K, Eljaszewicz A, Moniuszko M, et al. New treatment of wound healing with allogenic acellular human skin graft: preclinical assessment and in vitro study. Transplant Proc. 2020;52(7):2204-7.

30. Pliszczynski J, Nita M, Kowalewski C, Wozniak K, Eljaszewicz A, Moniuszko M, et al. Transplantation of a new biological product in rare diseases, such as epidermolysis bullosa: response and clinical outcome. Transplant Proc. 2020;52(7):2239-43.

31. MacNeil S. Progress and opportunities for tissueengineered skin. Nature. 2007;445(7130):874-80.

32. Varkey M, Ding J, Tredget EE. Advances in skin substitutes-potential of tissue engineered skin for facilitating anti-fibrotic healing. J Funct Biomater. 2015;6(3):547-63.

33. Green H, Kehinde O, Thomas J. Growth of cultured human epidermal cells into multiple epithelia suitable for grafting. Proc Natl Acad Sci USA. 1979;76(11):5665-8.

34. Bell E, Ehrlich HP, Sher S, Merrill C, Sarber R, Hull B, et al. Development and use of a living skin equivalent. Plast Reconstr Surg. 1981;67(3):386-92.

35. Boyce ST. Skin substitutes from cultured cells and collagen-GAG polymers. Med Biol Eng Comput. 1998;36(6):791-800.

36. Kuroyanagi $\mathrm{Y}$, Kenmochi M, Ishihara S, Takeda A, Shiraishi A, Ootake N, et al. A cultured skin substitute composed of fibroblasts and keratinocytes with a collagen matrix: preliminary results of clinical trials. Ann Plast Surg. 1993;31(4):340-9 (discussion 9-51).

37. Lee SB, Jeon HW, Lee YW, Lee YM, Song KW, Park $\mathrm{MH}$, et al. Bio-artificial skin composed of gelatin and (1->3), (1->6)-beta-glucan. Biomaterials. 2003;24(14):2503-11.

38. Lepow BD, Downey $M$, Yurgelon J, Klassen L, Armstrong DG. Bioengineered tissues in wound healing: a progress report. Expert Rev Dermatol. 2011;6(3):255-62.

39. Zaulyanov L, Kirsner RS. A review of a bi-layered living cell treatment (Apligraf) in the treatment of venous leg ulcers and diabetic foot ulcers. Clin Interv Aging. 2007;2(1):93-8.

40. Falabella AF, Valencia IC, Eaglstein WH, Schachner LA. Tissue-engineered skin (Apligraf) in the healing of patients with epidermolysis bullosa wounds. Arch Dermatol. 2000;136(10):1225-30.

41. Halim AS, Khoo TL, Mohd Yussof SJ. Biologic and synthetic skin substitutes: an overview. Indian J Plast Surg. 2010;43(Suppl):S23-8.

42. MacNeil S. Biomaterials for tissue engineering of skin. Mater Today. 2008;11(5):26-35.

43. Grocott P, Blackwell R, Weir H, Pillay E. Living in dressings and bandages: findings from workshops with people with epidermolysis bullosa. Int Wound J. 2013;10(3):274-84.

44. Horwitz EM, Prockop DJ, Gordon PL, Koo WW, Fitzpatrick LA, Neel MD, et al. Clinical responses to bone marrow transplantation in children with severe osteogenesis imperfecta. Blood. 2001;97(5): 1227-31. 
45. Dominici M, Marino R, Rasini V, Spano C, Paolucci $\mathrm{P}$, Conte $\mathrm{P}$, et al. Donor cell-derived osteopoiesis originates from a self-renewing stem cell with a limited regenerative contribution after transplantation. Blood. 2008;111(8):4386-91. 